\title{
Associative symmetry as measured in the B-Ar paradigm: A stage analysis*
}

\author{
RICHARD C. NEY and ROBERT L. SOLSO $\dagger$ \\ Loyola University, Chicago, Illinois 60626
}

\begin{abstract}
The principle of associative symmetry was examined by using the indirect measure of the B-Ar paradigm. Sixty Ss were randomly assigned to three paradigmatic conditions (C-D, A-Br, B-Ar). The results indicated that bidirectional learning may be asymmetrical when the learning is viewed in stages.
\end{abstract}

Among the most controversial learning issues in contemporary verbal learning is the concept of associative symmetry. As originally proposed by Asch and Ebenholtz (1962), as S learns a specific forward association he learns a corresponding backward association. A popular method of evaluating bidirectionality of paired learning as a form of incidental learning, as introduced by Feldman and Underwood (1957) and Jantz and Underwood (1958), consisted of simply asking $S$ to recall the stimulus term in the presence of the response term after some degree of initial forward learning. Although the above experiments yielded less stimulus recall than response recall, the question of whether or not associative symmetry was present could not be completely resolved, since the technique did not account for the availability of the stimulus term. In an early experiment by Asch and Ebenholtz (1962), the stimuli were made available by having the Ss learn the paired-associate terms prior to associative learning; however, several Es have pointed out the inadequacy of this technique by citing evidence which indicates that prefamiliarization could lead to abnormal effects of inhibition or facilitation (Simon \& Wood, 1964; Underwood \& Schulz, 1960).

Leicht and Kausler (1965) recognized that Ss may fractionate the stimulus term in paired-associate learning, but are then asked to recall the nominal stimulus as a test of bidirectionality. They employed a recognition task as a measure of associative symmetry in an effort to reduce the disparity between functional and nominal stimuli. In a more recent experiment designed to test the influence of first list learning on associative symmetry, while at the same time operationally reducing the disparity between the functional and nominal stimulus, Wollen, Fox, and Lowry (1970) used high-imagery nouns as stimuli and response terms.

Ney and Solso (1972) examined associative symmetry by using an indirect measure of R-S learning. The B-Ar paradigm (cf. Murdock, 1956) was proposed as a

*The results of this experiment were reported at the American Psychological Association Meeting, September, 1974, New Orleans.

tRequests for reprints should be sent to R. L. Solso, Psychology Department, Loyola University of Chicago, 6525 North Sheridan Road, Chicago, Illinois 60626. measure of associative symmetry when compared with the $\mathrm{A}-\mathrm{Br}$ and $\mathrm{C}-\mathrm{D}$ paradigms. Bidirectional learning was measured by employing high-imagery and high-concrete terms as stimuli in association with low-meaningful trigrams as responses, in addition to examining the results of the backward paradigm (B-Ar) in relation to the re-paired paradigm (A-Br). The results showed nearly identical performance for the transfer conditions; however, it could be argued that, because of the nature of the response terms, the B-Ar paradigm had actually engendered less interference than the A-Br paradigm.

Stimulus availability is not the only problematic methodological consideration in the test for bidirectionality, as the direction of pairing must be equally difficult for both the forward and backward learning conditions (cf. Guirintano, 1972; Wollen, 1968).

The present study is a further attempt to use associative interference in negative transfer paradigms as a technique of confirming associative symmetry. It was hypothesized that the negative transfer paradigms ( $\mathrm{A}-\mathrm{Br}$ and B-Ar) would be an effective means of isolating the associative stage of learning. The use of the re-paired paradigm also neutralized the potential problem of forward rehearsal during the R-S transfer task.

\section{METHOD}

The design was a single-level design, with effect or transfer paradigm as the variable (A-Br, B-Ar, C-D) and a trials criterion measure as the dependent variable. The stimulus and response components, as scaled by Paivio, Yuille, and Madigan (1968), were above 6.60 for both imagery and concreteness. The 36 nouns were selected to minimize intralist similarity and then randomly assigned to four lists of nine stimulus and response pairs. The imagery and concreteness variables were held constant because of the possibility of direction-of-pairing difficulty for the paired-associate pairs.

The Ss were introductory psychology students whose participation partially fulfilled a course requirement. A total of 64 Ss were equally divided among the three paradigm conditions. Four Ss were eliminated for failure to follow instructions.

The pairs were presented on a Stowe memory drum using a standard anticipation method until $S$ reached a criterion of two perfect or a maximum of 20 trials. The intratrial time was $2.2 \mathrm{sec}$ and intertrial time was $4 \mathrm{sec}$. All Ss were instructed to pronounce aloud first the A and then the B term on the first trial of both the original and transfer lists. Guessing was encouraged. 
Following first list acquisition Ss were given a transfer list. Second list responses had to be correctly paired with their respective stimuli in order to be considered correct. A criterion of one perfect trial for each of the transfer paradigms $(\mathrm{A}-\mathrm{Br}$, B-Ar, C-D) was required.

\section{RESULTS AND DISCUSSION}

A planned comparison of the three transfer conditions was conducted on the trials to criterion. The mean number of trials to criterion for the C-D, A-Br, and $\mathrm{B}-\mathrm{Ar}$ paradigms were $6.45,8.10$, and 8.50 , respectively. The data confirmed the hypothesis of significant negative transfer for both of the re-paired paradigms in relation to the C-D control paradigm. $\mathrm{F}(1,57)=4.42, \mathrm{p}<.05$. Both of the re-paired conditions showed equal transfer effects.

Observation of the data revealed no differential rates of learning on the A-B list; therefore, any differences in trials to criterion on the transfer could not be ascribed to differences in the amount learned during initial acquisition.

The successive criterion scores for the three transfer paradigms are shown in Fig. 1. The statistical technique employed by Wollen, Fox, and Lowry (1970) was used. Those Ss who reached criterion in fewer than 20 trials were given scores of $100 \%$ for the remaining trials. As may be seen, the A-Br and B-Ar paradigms showed symmetrical learning at a criterion score of one and later at scores six through nine.

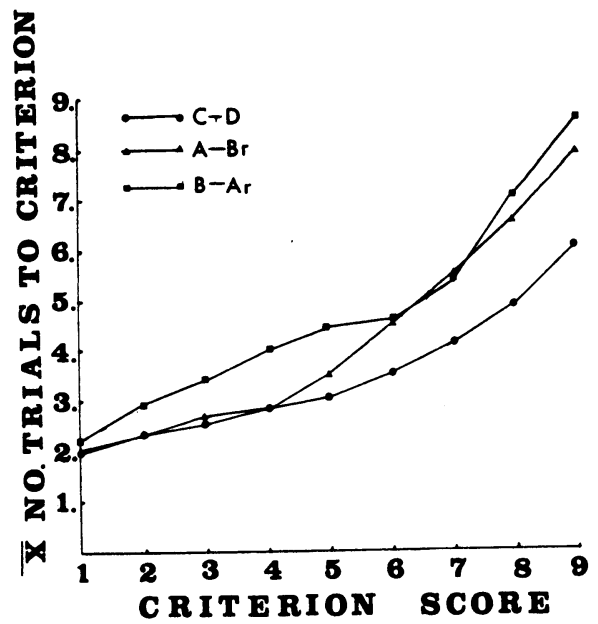

Fig. 1. Successive criterion curves of three transfer paradigms.
As shown in Fig. 1, the amount of interference generated by the $\mathrm{A}-\mathrm{Br}$ and $\mathrm{B}-\mathrm{Ar}$ paradigms was equal at the first criterion score and again at a criterion score of six. Thus, at certain stages of learning, the amount of interference generated from forward and backward associations was equal. However, as in the Wollen, Fox, and Lowry (1970) experiment, the data showed differences during the intermediate levels of learning. Between criterion scores of two and five, the $\mathrm{A}-\mathrm{Br}$ paradigm showed little evidence of negative transfer, while the B-Ar condition showed increasing negative transfer. At this stage of learning the interference engendered by backward associations seems to be greater than that of the forward association.

Bidirectional learning may appear.to be symmetrical if one looks at only the transfer data collected at the end of learning or at one perfect trial, however, contrary results are obtained if one measures the effect of the forward and backward associations at the intermediate stages of learning. The results of the present experiment indicate that asymmetry is obtained if the degree of learning is viewed in stages.

\section{REFERENCES}

Asch, S. E., \& Ebenholtz, S. M. The principle of associative symmetry. Proceedings of the American Philosophical Society, 1962, 106, 135-163.

Feldman, S. M., \& Underwood, B. J. Stimulus recall following paired-associate learning. Journal of Experimental Psychology, 1957. 53. 11-15.

Guirintano, S. L. Directionality of associations in paired-associate learning. Journal of Experimental Psychology, $1972,95,463-464$.

Jantz, E. M., \& Underwood, B. J. R-S learning as a function of meaningfulness and degree of $S-R$ learning. Journal of Experimental Psychology, 1958, 56, 174-179.

Leicht, K. L., \& Kausler, D. H. Functional stimulus learning as related to degree of practice and meaningfulness. Journal of Experimental Psychology, 1965, 69, 100-101.

Murdock, B. B., Jr. "Backward" learning in paired-associates. Journal of Experimental Psychology, 1965, 51, 213-215.

Ney, R. C., \& Solso, R. L. Associative symmetry and the B-Ar paradigm. Paper presented at the meeting of the Midwestern Psychological Association, Cleveland, May 1972.

Paivio, A. Yuille, J. C., \& Madigan, S. A. Concreteness, imagery and meaningfulness values for 925 nouns. Journal of Experimental Psy chology, 1968, 76(1, Part 2).

Simon, S., \& Wood, G. Backward learning and the stimulus-familiarization inhibitory effect. Journal of Experimental Psychology, 1964, 67, 310-315.

Underwood, B. J., \& Schulz, R. W. Meaningfulness and verbal learning. Philadephia: Lippincott, 1960.

Wollen, K. A. Effects of maximizing availability and minimizing rehearsal upon associative symmetry in two modalities. Journal of Experimental Psychology, 1968, 77, 626-630.

Wollen, K. W., Fox, R. A., \& Lowry, D. A. Variations in asymmetry as a function of degree of forward learning. Journal of Experimental Psychology, 1970, 86, 416-419.

(Received for publication June 17, 1974.) 